\title{
Properties of Epoxy-Asphalt Pavement Mixture for Bridge Decks
}

\author{
Amjad H. Albayati \\ Civil Engineering Dept. \\ University of Baghdad, IRAQ \\ A.khalil@uobaghdad.edu.iq \\ Esraa T. Al-Azawee \\ Civil Engineering Dept. \\ Al-Mansour University College, Baghdad, IRAQ \\ esraa.thamir@muc.edu.iq
}

\author{
Received: 19-Oct.-2017 Revised: 26-Nov.-2017 Accepted: 7-Jan.-2018 \\ http://doi.org/10.29194/NJES21010020
}

\begin{abstract}
Improving the ability of asphalt pavement to survive the heavily repeated axle loads and weathering challenges in Iraq has been the subject of research for many years. The critical need for such data in the design and construction of more durable flexible pavement in bridge deck material is paramount. One of new possible steps is the epoxy asphalt concrete, which is classified as a superior asphalt concrete in roads and greatly imparts the level of design and construction. This paper describes a study on 40-50 penetration graded asphalt cement mixed with epoxy to produce asphalt concrete mixtures. The tests carried out are the Marshall properties, permanent deformation, flexural fatigue cracking and moisture damage. Epoxy asphalt mixes performed better on resistance to fatigue and permanent deformation. They also performed significantly better on low-temperature properties and resistance to moisture damage. The addition of 30 percent of epoxy (by weight of asphalt cement) resulted in increase of Marshall stability by 39.8 percent, improve the tensile strength ratio by 22.9 percent, lowering both the rate of permanent deformation by 26.8 percent and the fatigue accumulation coefficient by 53.5 percent, in comparison with control HMA. Based on the above findings, it is recommended to use epoxy asphalt mixes as an optimal material for paving bridges deck in Iraq since it showed good prospects for this application due to the valuable performance and durability improvement.
\end{abstract}

Keywords: Asphalt, Epoxy Asphalt Concrete, Fatigue, Permanent Deformation.

\section{Introduction}

Epoxy asphalt concrete system was used in the past decade to enhance the skid resistance of bridge decks, and to increase the service life span of pavement by limiting cracking and deformation. For decks in bridges, higher strains in asphalt are usually developed [1]. Epoxy Asphalt Concrete (EAC) is a kind of high strength and flexible material introducing thermosetting epoxide resin and solidified agent into asphalt [2]. Characterizations of EAC refer to the ability of this material to satisfy the function of pavement on an orthotropic steel deck due to its special properties. EAC is a type of polymer concrete obtained by adding epoxy resins with a special hardener to be mixed with asphalt and aggregates. After curing, the EAC will be beyond the melting point. According to [3], the thermoset materials have better resistance to fatigue and rutting that may affect the pavement of steel bridge decks.

In 2011[4] satisfied the purpose on how could the EAC serve as a pavement and improving the following:

1. Skid resistance.

2. Flat riding of surface.

3. Waterproofing of the deck.

4. Durability and resistance to cracking.

5. Resistance to rutting and shoving.

Epoxy is categorized as thermoplastic polymer. It exhibits hardness, strength and heat resistance. Generally, thermoplastic stiffen the bitumen. Study done by( Downes et al. 1988) shows that the epoxy modified bitumen is twelve times the cost of normal bitumen. However, the performance of the product in terms of fatigue and permanent deformation would appear to be in excess of ten times than normal AC.

\section{Experimental Work \\ 2.1 Raw Materials}

The 40-50 grade asphalt was used in this study obtained from Aldura refinery located in south of Baghdad with a penetration of $44 \mathrm{~mm}$ at $25^{\circ} \mathrm{C}$, softening point of $48{ }^{\circ} \mathrm{C}$ and viscosity of 0.34 Pa.s at $135^{\circ} \mathrm{C}$.Epoxy asphalt comprises asphalt binder mixed with epoxy, which is added and mixed with graded aggregates. The term epoxy asphalt binder refers to blend of epoxy resin, curing agent and asphalt cement, while Epoxy Asphalt Concrete (EAC) is terms to epoxy asphalt binder and aggregates. Along with this approach, FOSROC epoxy Nitocote EP $\mathbf{4 0 5}$ was used as a primary modified agent; the main characteristic of this material is located in table 1 , it comprises with two different chemical materials, the first component was Bisphenol-A (epoxy resin) and the second one aromatic amine hardener (epoxy base hardener) -B used to increase the speed of reaction. In this study epoxy, modified asphalt was produced by adding the two epoxy components in a mass ratio of $\mathrm{A}: \mathrm{B}$ 
equal to 85:15, and then adding the blend to the asphalt cement, the materials thoroughly mixed by using electrical stirrer until reaching to a homogeneous mix to ensure good acceptable repeatable results of tests.

After mixing operation, the asphalt concrete at temperature of $155^{\circ} \mathrm{C}$ will become ready for mixing with epoxy in different ratio of $10 \%, 20 \%$ and $30 \%$ by weight of asphalt cement, which designated as E10, E20 and E30 for every epoxy contents.

Then, the epoxy asphalt concrete was mixed with aggregates to produce the EAC. Moreover, Aggregate used in this study was brought form Alnibae quarry located North West of Baghdad which detailed in Table 3. The thermal-setting nature of the epoxy asphalt used required curing of the mixes for $50 \mathrm{~min}$ at $120{ }^{\circ} \mathrm{C}$ prior to compaction. After compaction the mixes were cured for an additional $5 \mathrm{~h}$ at $120{ }^{\circ} \mathrm{C}$ before testing. Curing of the mixes is necessary to mobilize and ensure complete epoxy reaction with the asphalt and the procedures adopted were based on curing trends researched previously [5].

Table 1: Asphalt Test Results (Highway Material lab, University of Baghdad)

\begin{tabular}{|l|c|c|}
\hline Sample & $\begin{array}{c}\text { Penetration, } \\
\text { mm }\end{array}$ & $\begin{array}{c}\text { Softening } \\
\text { point }^{\mathbf{}} \mathbf{C}\end{array}$ \\
\hline 40/50 pen. & 44 & 48 \\
\hline Epoxy binder Based (part B) & 236 & 36 \\
\hline Epoxy Asphalt (part A and B) & 211 & 40 \\
\hline
\end{tabular}

Table 2 Detailed Information for Epoxy (Highway Material lab, University of Baghdad)

\begin{tabular}{|l|c|c|}
\hline \multirow{2}{*}{ Properties } & \multicolumn{2}{|c|}{ Typical Values } \\
\cline { 2 - 3 } & $\begin{array}{c}\text { Component A } \\
\text { (aromatic } \\
\text { amine) }\end{array}$ & $\begin{array}{c}\text { Component B } \\
\text { (Bisphenol) }\end{array}$ \\
\hline Appearances & Viscous & Liquid \\
\hline $\begin{array}{l}\text { Mass ratio of } \\
\text { mixing }\end{array}$ & $85.0 \%$ & $15.0 \%$ \\
\hline Viscosity @ 25 ${ }^{\circ} \mathrm{C}$ & $6342 \mathrm{MPa} . \mathrm{s}$ & $359 \mathrm{MPa} . \mathrm{s}$ \\
\hline Density @ $25^{\circ} \mathrm{C}$ & $1.41 \mathrm{gm} / \mathrm{cm}^{3}$ & $1.01 \mathrm{gm} / \mathrm{cm}^{3}$ \\
\hline Color & Black & White \\
\hline
\end{tabular}

\subsection{Marshall Properties}

Initially 24 Marshall Samples were produced having 4.8 percent bitumen content for the types (HMA, E10, E20 and E30) of the samples. The samples were then sub-divided in two groups of 12 mixes. The average specific gravity in each group was equal. The first group was immersed in water at $60{ }^{\circ} \mathrm{C}$ for $30 \mathrm{~min}$ and then tested up to failure using concaved steel loadings plates. The ratio of stability to flow, which is the Marshall quotient (M1) was obtained and hence an indication of the stiffness was obtained.

It should be noted that the MQ is a measure of mix resistance to shear and permanent deformation and hence rutting [6]. The second group of samples was immersed in water at $60{ }^{\circ} \mathrm{C}$ for 24 hrs. The samples were then tested up to failure. The ratio of M2 of stability to flow was obtained. The retained Marshall stability (MSR) was obtained by using the average stability of each group:

Where:

$$
\text { MSR }=\frac{\text { MScond }}{\text { MSuncond }} \times 100
$$

MSR: is the Marshall retained stability.

$\mathrm{M}_{\text {Scond }}$ : is the average Marshall stability for conditioned samples $(\mathrm{kN})$.

$\mathrm{M}_{\text {Suncond }}$ : is the average Marshall stability for unconditioned samples $(\mathrm{kN})$.

The ratio of stabilities for conditioned and unconditioned cases can be considered as the criterion for moisture susceptibility of the mix. [6].

In the present study, a crushed limestone was used. Table 3 gives the physical properties of this aggregate and Table $\mathbf{4}$ and Fig $\mathbf{2}$ give the wearing course gradation. The Marshall stability of HMA and EAC prepared by E10, E20 and E30 were measured and the results obtained are shown in Fig. 5, the results indicate that the lowest marshall stability corresponds to HMA mix. The highest result corresponds to the 30 percent epoxy modified asphalt. The mixes E20 and E30 have highest and lowest flow values respectively. Approximately all mixes have similar Marshall Quotients with a maximum difference of 5\%.

Table 3: Alnibae Aggregate Properties (Highway Material lab, University of Baghdad)

\begin{tabular}{|c|c|c|c|}
\hline \multirow[b]{2}{*}{ Property } & \multicolumn{2}{|c|}{ Alnibae Aggregate } & \multirow[b]{2}{*}{ SCRB/R9,2003 [10] } \\
\hline & $\begin{array}{c}\text { Coarse } \\
\text { Aggregate }\end{array}$ & $\begin{array}{c}\text { Fine } \\
\text { Aggregate }\end{array}$ & \\
\hline Bulk Specific gravity (g/cm3) (ASTMC127 and C128) & 2.646 & 2.63 & $\begin{array}{ll}---- \\
\end{array}$ \\
\hline Apparent Specific gravity (g/cm3) (ASTM C127 and C128) & 2.656 & 2.667 & ----- \\
\hline Percent water absorption (ASTM C127 and C128) & 0.14 & 0.523 & 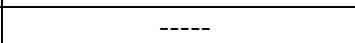 \\
\hline (Los-Angeles Abrasion) Percent wear (ASTM C131) & 19.69 & & 30 Max \\
\hline Fractured pieces, \% & 98 & & 90 Min \\
\hline Sand Equivalent(ASTM D 2419) & & 55 & 45 Min*.Superpave (SP-2), \\
\hline Soundness loss by sodium sulfate solution,\% ( C-88) & 3.4 & ------- & $12 \operatorname{Max}$ \\
\hline
\end{tabular}




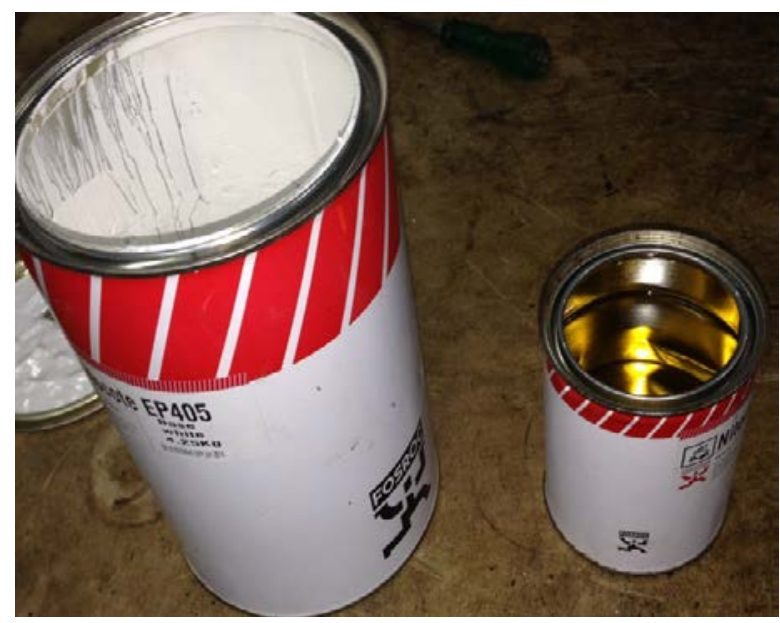

Figure 1 FOSROC Epoxy Nitocote EP 405

Table 4 Gradation of Aggregate

\begin{tabular}{|l|c|c|c|c|c|c|c|}
\hline Sieve size (in) & $3 / 4$ & $1 / 2$ & $3 / 8$ & No.4 & No.8 & No.50 & No.200 \\
\hline $\begin{array}{l}\text { Selected gradation, } \\
\text { Passing (\%) }\end{array}$ & $\mathbf{1 0 0}$ & $\mathbf{9 5}$ & $\mathbf{8 8}$ & $\mathbf{6 5}$ & $\mathbf{3 9}$ & $\mathbf{1 4}$ & $\mathbf{5}$ \\
\hline
\end{tabular}

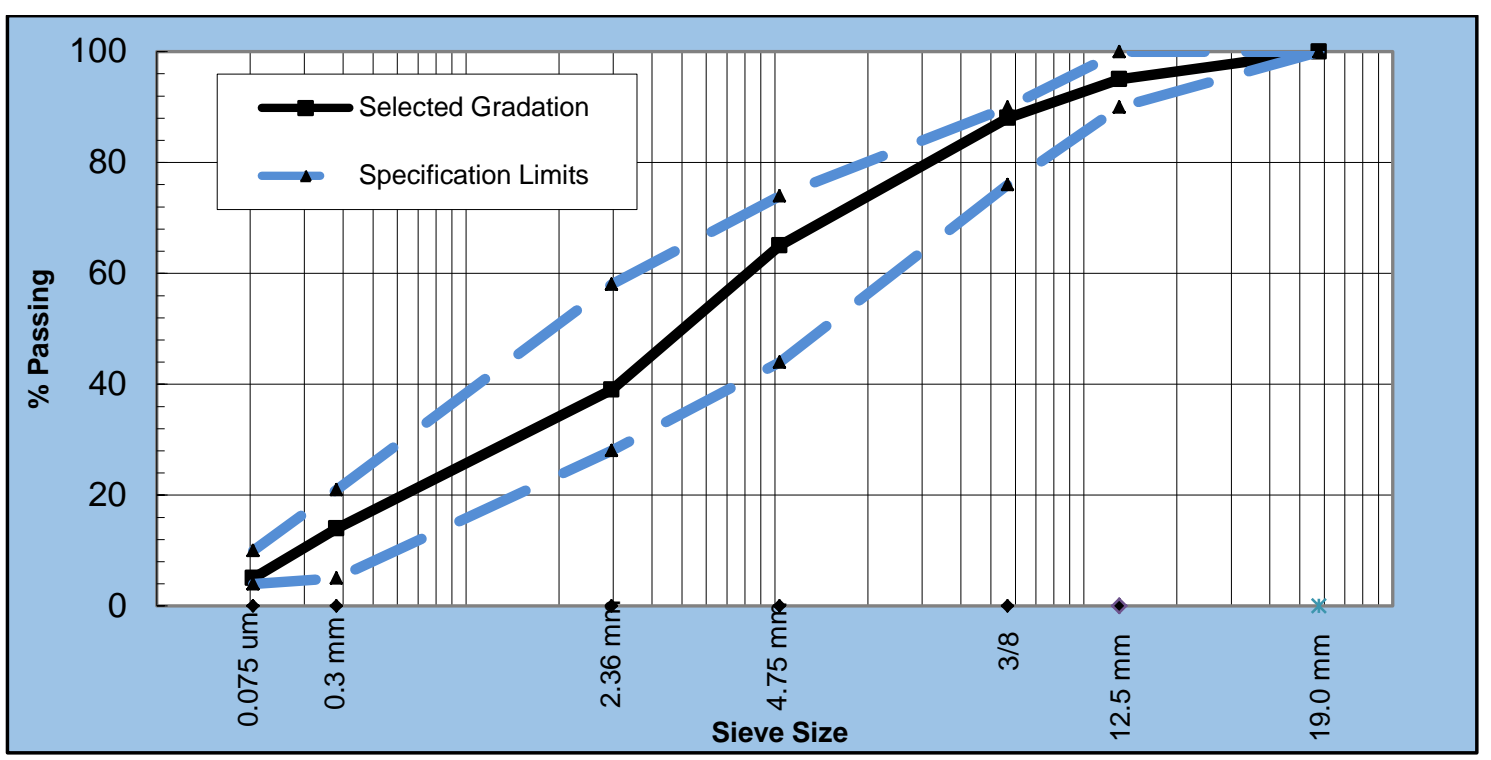

Figure 2 Aggregate Gradation Plot

\section{Mixture Tests}

\subsection{Indirect Tensile Strength Test:}

In this test (ITS), cylindrical samples were tested using a similar test assembly as that for concrete cylindrical in splitting test but using the Marshall loading testing machine. The samples fails by splitting along the loaded plane. The maximum load carried by a sample at failure is $\mathrm{P}$ and the splitting tensile strength is ITS:

$$
\text { ITS }=\frac{2 \mathrm{P}}{\pi \mathrm{LD}}
$$

Where: L:is the cylinder length (m); D:is the cylinder diameter (m).

The ITS values is a measure of moisture susceptibility of the asphalt mix, ASTM D 4867.
Totally, 24 samples were made for each group of mix, three unconditioned (dry) and three conditioned (wet) samples were tested. The Wet samples were subjected to successive cycles of freezing and thawing. Each cycle including 16 hours at $(-18$ oC) freezing followed by immersing in water bath at 60 oC for 24 hrs. The dry samples were placed in water for one hour at (25 $0 \mathrm{C}$ ) before testing. The ratio (TSR) is defined as:

$\mathrm{TSR}=\frac{\mathrm{P}_{\text {cond }}}{\mathrm{P}_{\text {uncond }}} \times 100$

Where: Pcond and Puncond are the failure loads for the conditioned and unconditioned samples respectively. According to ASTM D4867, the TSR must be higher than $80 \%$. 


\subsection{Permanent Deformation}

The Pneumatic Repeated load (PRLS) can be considered as a rutting measure of EAC mixes[9], cylindrical specimens dimension $101.6 \mathrm{~mm}$ (4 in) diameter $\times 203.2 \mathrm{~mm}(8 \mathrm{in})$ height were used. The specimens produced for this study needed approximately 3650 grams of mixture each in order to fabricate one specimen that according to mix design formula. The mix design method uses volumetric optimum asphalt content for each EAC contents. The specimens used in the Permanent Deformation were prepared using the Superpave Gyratory Compactor.

The test was performed at single deviator stress level of $138 \mathrm{kPa}(20 \mathrm{psi})$ and temperature of $40{ }^{\circ} \mathrm{C}$. the test consist of applying 10,000 compressive load cycles. Each cycle consist of 0.1 -second rectangular wave load followed by a

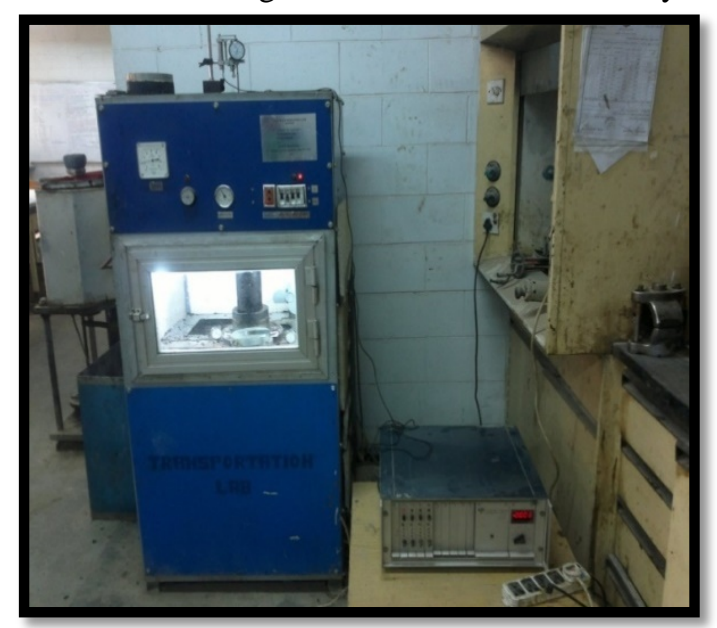

Figure 3 Permanent Deformation Specimens during the Test (Highway Material lab, University of Baghdad)

\subsection{Fatigue Cracking}

A sample of dimeter $150 \mathrm{~mm}$ and of thickness $50 \mathrm{~mm}(150 \times 50 \mathrm{~mm})$ has subjected to a vertical load along its vertical diametral axis and the horizontal deformations were measured using two axis is measured by two Linear Variable Differential transducers (LVDTs).The fatigue strength was obtained by means of Indirect Tensile Fatigue Test (ITFT) (BS DD AFB: 2002). The sample repeated compressive forces along its vertical dimetral axis its vertical dimetral axis. At fatigue failure the samples cracks vertical. The maximum tensile stress in the sample is:

$$
\sigma_{o}=\frac{2 P}{\pi \times d \times t}
$$

Where:

$\sigma_{o}=$ maximum stress (tensile) $(\mathrm{kPa}) ; \mathrm{d}=$ sample diameter $(\mathrm{mm})$; and the terms $(\mathrm{P})$ and $(\mathrm{t})$ are defined earlier. The fatigue life is considered to be the number of cycles $\left(N_{f}\right)$ that causes a complete failure of the sample, Fig. 4 when vertical displacement reaches $9 \mathrm{~mm}$.

For the (ITS) test, the initial tensile strain $\epsilon_{o}$ at the center of the sample is: rest of 0.9 second to determine the permanent deformation characteristics of paving materials. In this study, permanent axial deformation properties of the pavement. The deformation was measured using Linear Variable Differential Transformer (LVDT) as shown in Fig. 3.The permanent strain $\left(\epsilon_{P}\right)$ is:

$$
\epsilon_{P}=\frac{P_{d} \times 10^{6}}{h}
$$

Where: $P_{d}=$ permanent axial deformation, $\mathrm{h}=$ sample thickness

The resilient strain in the sample is:

$$
\epsilon_{r}=\frac{\Delta \mathrm{r}}{\mathrm{h}}
$$

Where:

$\Delta \mathrm{r}=$ resilient deformation $=\Delta_{\mathrm{rh}}-\Delta_{\mathrm{rl}}, \Delta_{\mathrm{rh}}=$ high reading of LVDT, $\Delta_{\mathrm{rl}}=$ low reading of LVDT.

$$
\epsilon_{o}=\frac{\sigma \times(1+3 v)}{E_{o}} \times 1000
$$

Where

$\epsilon_{0}$ : is the stiffness modulus corresponding to stress $\sigma_{o}$.All tests were carried out at temperature of $20^{\circ} \mathrm{C}$

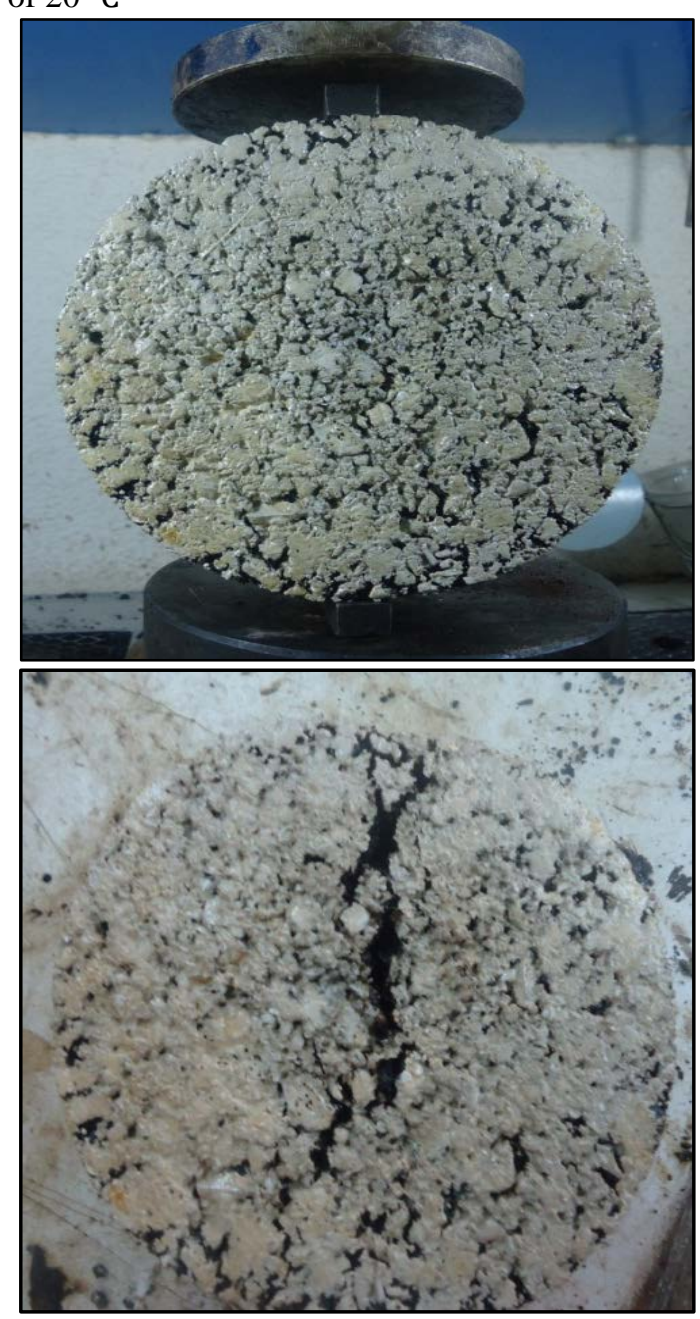

Figure 4 IDT Fatigue Test 


\section{Results and Discussion:}

\subsection{Test on HMA and EAC mixes:}

The test result for Marshall Stability and flow are given in Table $\mathbf{5}$ for each mix, the values were averaged and shown in Fig. 5 and Fig. 4 shows the variation of Marshall Stability and the mix types. Fig. 6 shows the effect sample conditioning on the MQ values as related to the type of mix. It is evident that increasing the Fig. 6 indicates that the unconditioned samples shows higher MQ values for any epoxy percentage. Samples containing lime have higher epoxy content has increased the Marshall Stability and the stiffness of binder.

The Marshall Stability has been increased by $7.9 \%, 25.3 \%$ and $39.8 \%$ corresponding to $10 \%, 20 \%$ and $30 \%$ of epoxy contents respectively. The above increments in stability values were $11.2,21.1$, and $35.9 \%$ for same epoxy asphalt. These findings indicate that the EAC mixes are more resilient to moisture.

stiffness and hence higher MQ values. The higher values of Indicate a better shear resistance, less permanent deformation and less rutting.

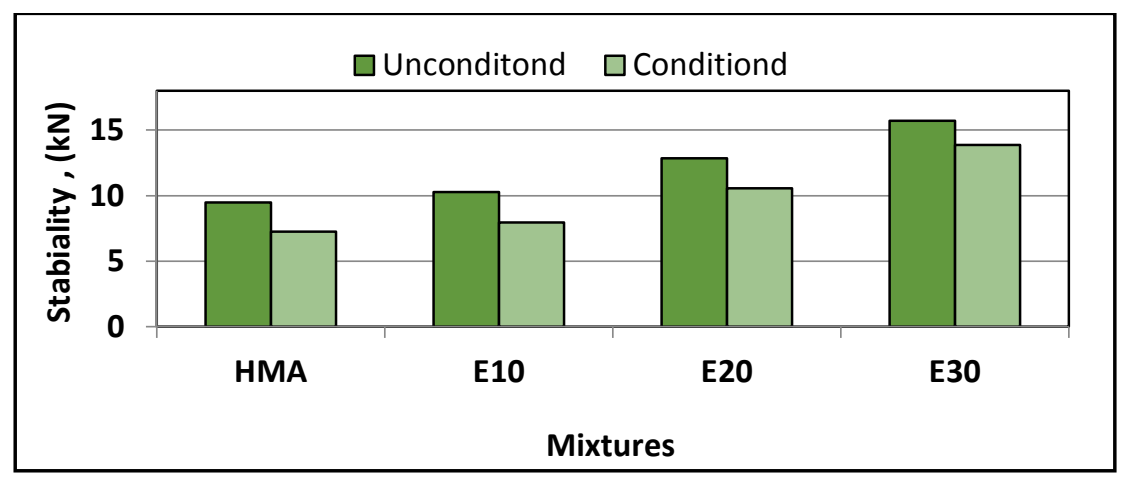

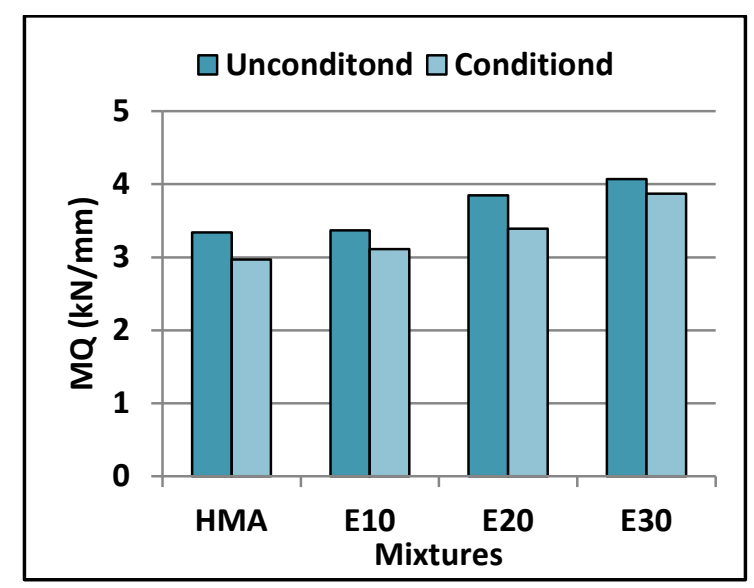

Figure 6 MQ Result for HMA and EAC Mixtures

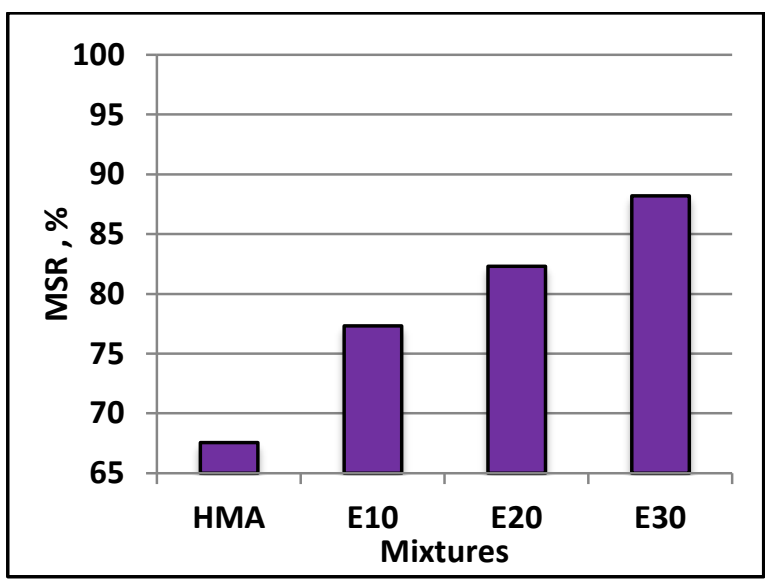

Figure 7 Effect of EAC on Retained Marshall Stability

Table 5 Mixture properties for Marshall test.

\begin{tabular}{|c|c|c|c|c|c|c|c|}
\hline Mixtures & $\begin{array}{c}\text { Stability, } \\
\text { M1 }\end{array}$ & $\begin{array}{c}\text { Flow,F1 } \\
(\mathbf{m m})\end{array}$ & $\begin{array}{c}\text { MQ1 } \\
\frac{\text { M1 }}{\mathrm{F} 1}(\mathrm{kN} / \mathbf{m m}) \\
\end{array}$ & $\begin{array}{c}\text { Stability, } \\
\text { M2 }\end{array}$ & $\begin{array}{c}\text { Flow,F2 } \\
\text { (mm) }\end{array}$ & $\begin{array}{c}\text { MQ2 } \\
\frac{\text { M2 }}{\text { F2 }}(\mathrm{kN} / \mathrm{mm})\end{array}$ & $\begin{array}{c}\text { MSR } \\
\text { M2/M1 (\%) }\end{array}$ \\
\hline HMA & 9.47 & 2.76 & 3.34 & 7.25 & 2.44 & 2.97 & 76.55 \\
\hline E10 & 10.28 & 3.05 & 3.37 & 7.95 & 2.55 & 3.11 & 77.33 \\
\hline E20 & 12.84 & 3.24 & 3.85 & 10.57 & 3.11 & 3.39 & 82.32 \\
\hline E30 & 15.72 & 3.86 & 4.07 & 13.87 & 3.58 & 3.87 & 88.23 \\
\hline
\end{tabular}

\subsection{Effect of Epoxy Concrete and Freezing and Thawing on the Indirect Tensile Strength Test:}

Figure 8 shows the variation of TSR values with epoxy content for samples that have been subjected to one cycle of freezing and thawing. The reduction in tensile strength of freezing and thawing is higher when the mixture is without epoxy. The TSR values increase as the epoxy content increases.

The decrease in the tensile strength is due to the decrease in mixture adhesion and binder cohesion. Adding epoxy to asphalt will enhance both adhesion and cohesion. 
NJES, Vol.21 No.1, 2018

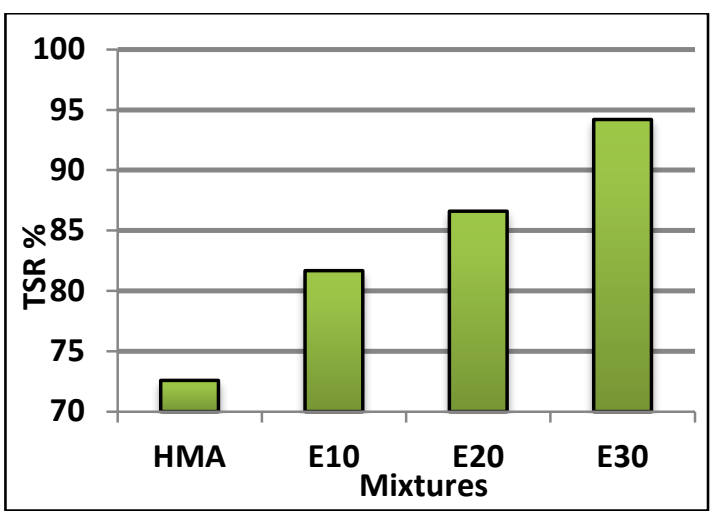

Figure 8 TSR Values for HMA and EAC Mixtures Under One (F-T cycle)

The tensile strength for all samples decreases after subjecting to the freezing a\% epoxy content has the higher TSR value which is 0.94 at the end of the cycle thawing cycle. It can be concluded that EAC serve better against the detrimental effect of moisture damage, hence TSR increase by 11.2, 17.2 and $22.9 \%$ with respect to the increment of epoxy content. As a result, the tensile strength ratio value of the locally developed epoxy asphalt mix is higher than that of HMA mixtures, indicating that the locally developed epoxy asphalt mix is less susceptible to moisture damage and could satisfy the minimum requirement of TSR of 80 percent.

\subsection{Permanent deformation}

The tests were conducted on epoxy asphalt mixes at $40{ }^{\circ} \mathrm{C}$, Fig.9 demonstrated the effect of adding epoxy to the asphalt with varying contents.

In this study, the power model was used to fit the accumulation of permanent deformation curve.

The slope and intercept of this model are indicators of rutting resistance [7].
Albayati \& Al-Azawee, pp.20-27

The permanent strain as related to number of cycles $\mathrm{N}$ is:

$\epsilon_{p}=\mathrm{aN}^{\mathrm{b}}$

Where: $\mathrm{a}$ and $\mathrm{b}$ are intercept and slope coefficients and $\mathrm{N}$ is the load repetition.

Where: $\mathrm{a}$ and $\mathrm{b}$ are intercept and slope coefficients and $\mathrm{N}$ is the load repetition.

As shown in Fig.9 the EAC mixtures showed superior effect toward the negative impact of repeated loading at moderate temperature of $40^{\circ} \mathrm{C}$, hence E20 and E30 exhibited more flatter curve with lower slope trend of 0.328 and 0.306 which yield decrease by 21.4 and $26.8 \%$ in the rate of permanent deformation curve due to the control mixture and this reason may be attributed to the increase of asphalt stiffens which contributed to reduce the permanent deformation effect as well as the intercept value and shows an increase in number of repetition to failure .Another possible aspect could be considered that the EAC mixtures showed lower permanent stain at 1000 repetition that represent the beginning of territory zone of permanent deformation, the EAC mixtures indicted a lower $\epsilon$ p especially for E20 and E30 and this behavior could be useful in preventing the early stage of damage after construction period. [9]

The test results indicate that the dynamic stability of EAC is better than that of conventional asphalt mixes. In addition, the accumulated deformation for E30is higher than those of EAC and HMA mixes. This finding is an evidence that EAC is a stabilized paving material at high temperature and can be used for paving steel bridge decks. Table 6 gives the permanent deformation modals for all mixes.

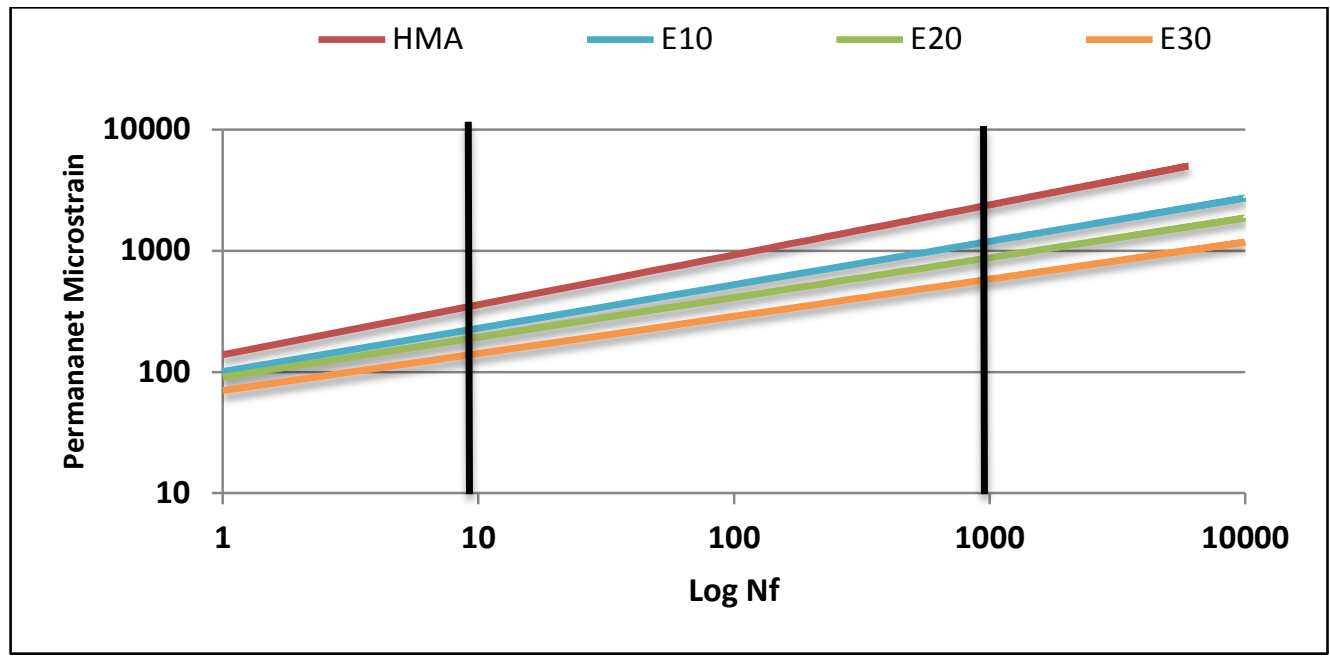

Figure 9: Permanent Deformation for HMA and EAC mixtures at $40{ }^{\circ} \mathrm{C}$ 
Table 6: Permanent Deformation Models for All Mixtures

\begin{tabular}{|c|c|c|c|c|}
\hline Mixture type & Model & $\mathbf{R}^{2}$ & $\boldsymbol{\epsilon}_{\boldsymbol{P}}$ at 1000 rep.(microstain) & $\begin{array}{c}\text { No. of } \\
\text { repetition }\end{array}$ \\
\hline HMA & $\epsilon_{P}=\mathbf{1 3 8 . 4 N}^{\mathbf{0 . 4 1 2 5}}$ & $\mathbf{0 . 9 9 3 7}$ & $\mathbf{2 7 3 0}$ & $\mathbf{6 4 2 5}$ \\
\hline E10 & $\epsilon_{P}=\mathbf{1 0 0 . 5 7 N}^{\mathbf{0 . 3 5 8 1}}$ & $\mathbf{0 . 9 7 9 2}$ & $\mathbf{1 1 9 7 . 9}$ & $\mathbf{8 4 2 7}$ \\
\hline E20 & $\epsilon_{P}=\mathbf{9 0 . 3 4 \mathbf { N } ^ { \mathbf { 0 . 3 2 8 7 } }}$ & $\mathbf{0 . 9 5 8 6}$ & $\mathbf{7 3 5 . 8 7}$ & $\mathbf{1 0 , 0 0 0}$ \\
\hline E30 & $\epsilon_{P}=\mathbf{7 0 . 1 1 3 N ^ { 0 . 3 0 6 4 }}$ & $\mathbf{0 . 9 5 1 1}$ & $\mathbf{4 1 8 . 7 1}$ & $\mathbf{1 0 , 0 0 0}$ \\
\hline
\end{tabular}

\subsection{Fatigue Cracking}

The fatigue life $N_{f}$ is related to the initial tensile strain as follows [8]:

$$
N_{f}=\mathrm{K} 1\left(\frac{1}{\epsilon_{o}}\right)^{\mathrm{K} 2}
$$

Where: $\mathrm{K} 1$ and $\mathrm{K} 2$ are constants related to the material type and test condition.Fig. 10 relates the initial tensile strain to the fatigue life $\left(N_{f}\right)$

It is evident that E30 shows higher endurance and fatigue life then that of the other two contents E1 and E20 with respect to HMA mixture. This behavior has been mainly attributed to the stiffness provided by epoxy content that could be influenced on fatigue life by increasing the number of repetition to fracture as well as

The initial tensile stress. The contents $\mathrm{k} 1$ and k2 of equation 9 are given in Table 7 together with the regression constant $\mathrm{R}^{2}$. The $\mathrm{k} 2$ value represents the susceptibility of the mix to strain. The mix E 30 was less susceptible to strain than the others. Furthermore, $\mathrm{R}^{2}$ values for the $\mathrm{E} 30$ were lower than those E10 and E30 as well as HMA mixtures. These differences were due to the size effect. Two criteria were followed, one was based on $\epsilon_{o}$ at 106 cycles and the other was based on the number of cycles at 200 macrostrain (N200). The calculated $\epsilon_{o}$ and N200 values are given in Table 7. It is evident that the two criteria agreed well.

As result of fatigue test, it can be seen that the fatigue life of the locally developed epoxy asphalt mix with E30 is more than approximately by three times greater than that of HMA mixtures.

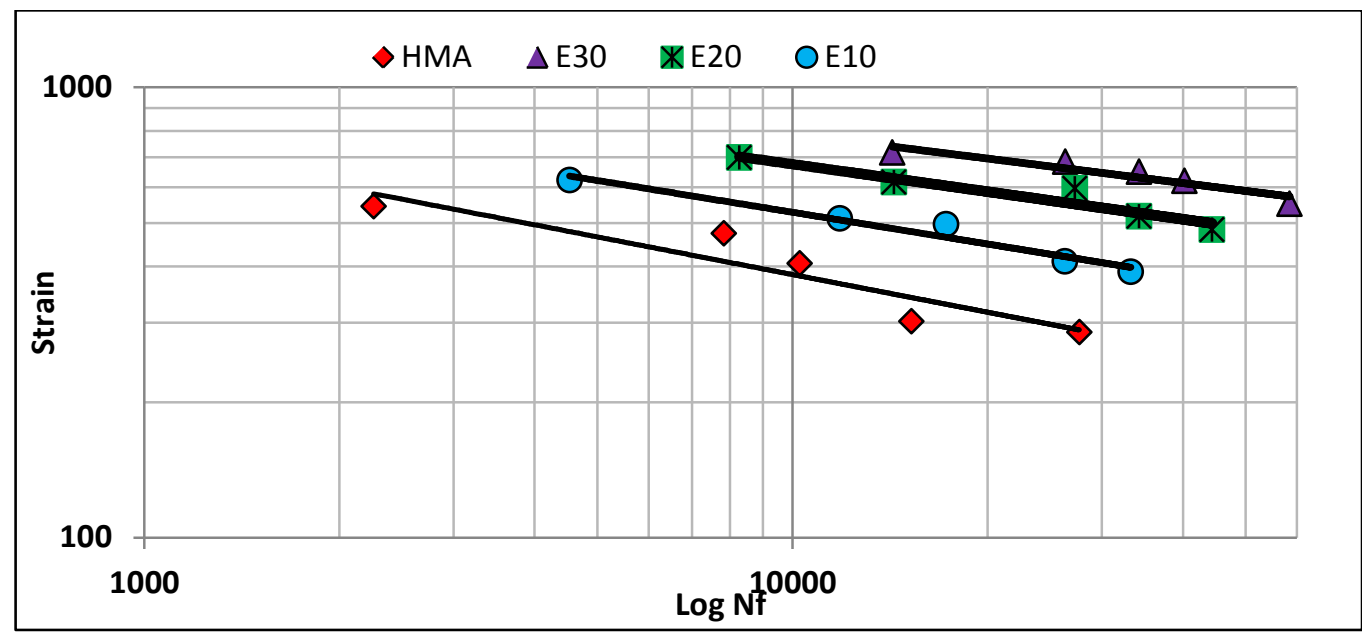

Figure 10: Relationship between fatigue life and initial strain

Table 7: Material constant and fatigue failure result

\begin{tabular}{|c|r|r|r|r|c|c|}
\hline Mixture & \multicolumn{1}{|c|}{$\mathrm{K} 1$} & $\mathrm{~K} 2$ & $\mathrm{R}^{2}$ & Fatigue function & $\boldsymbol{\epsilon}_{\boldsymbol{o}}(\mu \mathrm{m} / \mathrm{m})$ & N 200 cycles \\
\hline HMA & $5.10062 \mathrm{E}-09$ & 3.597 & 0.8595 & $\mathrm{Nf}=5.10062 \mathrm{E}-09\left(\frac{\mathbf{1}}{\boldsymbol{\epsilon}_{\mathbf{o}}}\right) 3.597$ & 65 & 10295 \\
\hline E10 & $9.90701 \mathrm{E}-11$ & 4.273 & 0.9579 & $\mathrm{Nf}=9.90701 \mathrm{E}-11\left(\frac{\mathbf{1}}{\epsilon_{o}}\right) 4.273$ & 80 & 17926 \\
\hline E20 & $2.39713 \mathrm{E}-12$ & 4.926 & 0.9057 & $\mathrm{Nf}=2.39713 \mathrm{E}-12\left(\frac{\mathbf{1}}{\epsilon_{o}}\right) 4.926$ & 95 & 21157 \\
\hline E30 & $6.93654 \mathrm{E}-14$ & 5.524 & 0.889 & $\mathrm{Nf}=6.93654 \mathrm{E}-14\left(\frac{\mathbf{1}}{\epsilon_{o}}\right) 5.524$ & 115 & 29229 \\
\hline
\end{tabular}

\section{Conclusions}

Based on the experimental results, the following conclusions are given:

1. The Marshall was increased by $7.9 \%, 25.3 \%$ and $39.8 \%$ for the epoxy contents of $10 \%, 20 \%$ and $30 \%$ respectively. For the conditioned samples, those increments were $11.2 \%, 21.1 \%$ and $35.9 \%$ for the same epoxy contents respectively.

2. The EAC mixtures have resisted moisture more than those without epoxy and the unconditioned samples containing E20 and E30 are of the highest MQ value. 
3. Adding epoxy to the asphalt, has enhanced adhesion and cohesion of the asphalt mix and improved the asphalt -aggregate bonding even in the presence of water.

4. After freezing and thawing, the tensile strength ratio decreases and also the TSR values increases as the epoxy content increases.The "E30" mix has a TSR value of 0.94 at the end of the first cycle. It can be concluded that the EAC serves better against the dimetral effect of moisture damage and hence the TSR increases by $11.2,17.2$ and $22.9 \%$ with respect to the increment of epoxy content.(10\%,20\% and 30\%).

5. Adding 30 percent of epoxy to the asphalt greatly enhanced the stability. The accumulated deformation for $\mathrm{E} 30 \mathrm{mix}$ is much less than those of E 10, E20 and HMA mixes. This indicates that EAC is highly stabilized in hot climates and can be in a good performance for pavement on steel bridge decks.

6. Fatigue life of the locally developed epoxy asphalt mix with E30 is more than approximately by three times greater than that of HMA mixtures. 7. Finally, adding 30 percent epoxy by weight of asphalt could be one of the possible steps to increase the endurance of HMA mixtures for bridge deck pavement.

\section{References}

[1] Héritie, B.R., F. Olard, M. Saubotand and S. Kraft, 2005. Design of Specific Bituminous Surfacing for Orthotropic Steel Bridge Decks: Application to the Millau Viaduct. Presented at 7th International Conference on the Bearing Capacity of Roads, Railways and Airfields, Trondheim.
[2] Bild, S., (1985) "Contribution to the improvement of the durability of asphalt pavement on orthotropic steel bridge decks”,(dissertation), Achen: RWTH Achen.

[3] Read J, Whiteoak D , (2003). The shell bitumen handbook. 5th ed. UK: Shell Bitumen.

[4] Xuejuan Cao1, Yunbo Lei, Wei Wang, BomingTang , (2011) , “A Curing Model for Epoxy Asphalt Concrete and Its Implementation for Construction" , International Journal of Pavement Research and Technology, Vol.4 No.3.

[5] Chen C, Qian ZD, Chen LL.,(2011) Research on the construction and strength increasing characteristic of local developed epoxy asphalt mixture. J Southeast University.

[6] Aksoy A, Samiloglu K, Tayfur S, Ozen H., (2005) "Effects of various additives on themoisture damage sensitivity of asphalt mixtures". Construction and Building Materials Volume 19, Issue 1, pp 11-18.

[7] Garba, R.,((2002) “Permanent deformation properties of asphalt concrete mixtures, $\mathrm{PhD}$ Thesis, Norwegian University of Science and Technology”.

[8] Monismith, C.L. ,Deacon, J.A. (1969), "Fatigue of asphalt paving mixtures". ASCE Transportation Engineering Journal 95(2): 317346.

[9] Albayati, H. K (2006) "Permanent Deformation Prediction of Asphalt Concrete Under Repeated Loading”,(dissertation), University of Baghdad. Iraq.

[10] SCRB/R9 (2003). General Specification for Roads and Bridges, Section R/9, Hot-Mix Asphalt Concrete Pavement, Revised Edition. State Corporation of Roads and Bridges, Ministry of Housing and Construction, Republic of Iraq

\section{خصائص خرسانة التبليط نوع الإسفلت ايبوكسي لرصفة الجسر}
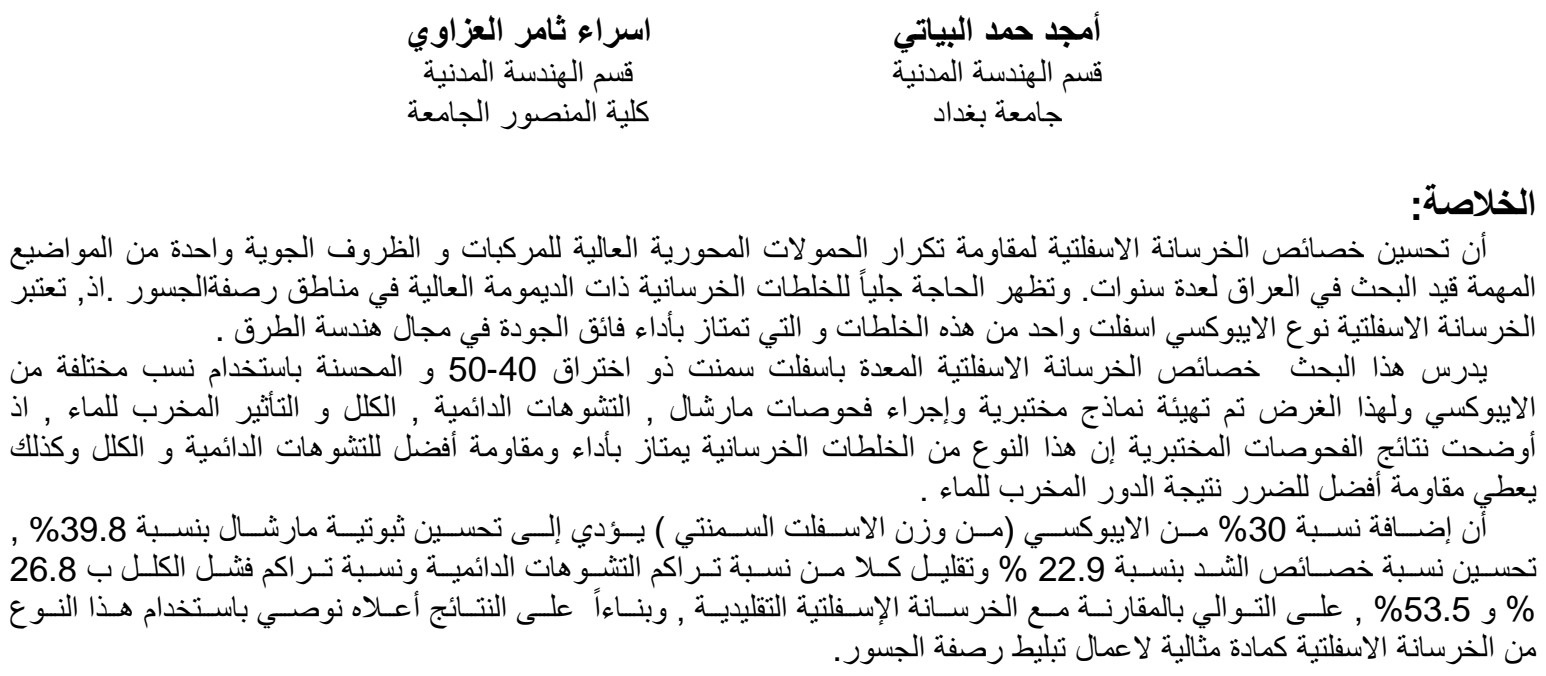